\title{
Anabases
}

ANABASES Traditions et réceptions de l'Antiquité

$7 \mid 2008$

Varia

\section{Pierre PONTIER, Trouble et ordre chez Platon et Xénophon}

Pascal Payen

(2) OpenEdition

Journals

Édition électronique

URL : http://journals.openedition.org/anabases/2579

DOI : 10.4000/anabases. 2579

ISSN : 2256-9421

Éditeur

E.R.A.S.M.E.

Édition imprimée

Date de publication : 1 mars 2008

Pagination : 300-302

ISSN : 1774-4296

Référence électronique

Pascal Payen, «Pierre pontier, Trouble et ordre chez Platon et Xénophon », Anabases [En ligne], 7 | 2008,

mis en ligne le 01 décembre 2011, consulté le 22 septembre 2020. URL : http://

journals.openedition.org/anabases/2579; DOI : https://doi.org/10.4000/anabases.2579

Ce document a été généré automatiquement le 22 septembre 2020.

(c) Anabases 


\title{
Pierre PONTIER, Trouble et ordre chez Platon et Xénophon
}

\author{
Pascal Payen
}

\section{RÉFÉRENCE}

Pierre PONTIER, Trouble et ordre chez Platon et Xénophon, Paris, Librairie philosophique J.

Vrin, 2006, $528 \mathrm{p}$.

60 euros / ISBN 2-7116-1843-9.

1 Au sens strict ce livre n'est pas à ranger parmi les études qui traitent de la réception de l'Antiquité. Mais sa richesse est telle, tant du point de vue des matériaux qu'il rassemble et analyse, que de la méthode qu'il met en œuvre, alliant sans cesse, notamment, philologie et histoire, qu'il nous a paru nécessaire d'en proposer ici une recension, pour porter cet ouvrage à la connaissance des littéraires, des historiens - du politique, des idées -, des philosophes, et plus encore de ceux qu'intéresse le croisement des disciplines. Ajoutons qu'un des deux protagonistes de cette étude, Xénophon, nous ramène dans le champ de l'historiographie, l'un des domaines couverts par les comptes rendus rassemblés dans cette section.

2 Pierre Pontier insiste d'emblée et résolument sur le contexte de son étude : un temps de crise, après le désastre de la guerre du Péloponnèse, où il s'agit, pour toux ceux qui sont de la génération née avec la guerre, de tenter de comprendre et de penser la défaite d'Athènes, et de l'intégrer à la réflexion et à l'action politiques. Or Xénophon, né vers 430 , et Platon, peu après, vers 428-425, appartiennent à ce temps et au même milieu, issus de l'aristocratie, formés dans le cercle de Socrate. Comment cette génération a-telle vécu le "trouble ", le désordre, le vacillement des repères générés par ce conflit majeur ? L'originalité de la démarche adoptée - et sans cesse adaptée à la complexité des dossiers documentaires - consiste à entrecroiser, avec une extrême rigueur et sans aucun dogmatisme d'école, l'analyse des mots, des concepts et des situations historiques, en concentrant le regard sur ce qui est cœur de la période, du moins dans 
les sources : l'expression linguistique du «trouble » (thorubos, tarakhè et tous les termes appartenant aux mêmes champs lexicaux et sémantiques). Mais « constater ce qu'est le trouble, c'est aussi envisager un ordre ", c'est penser un temps, une cité, un champ politique, des utopies qui, tout à la fois, intègrent les expériences passées des cités et y renoncent, pour envisager d'autres solutions, singulièrement dans le cas d'Athènes.

3 L'auteur part du constat que le concept d'ordre a joué un grand rôle dans la pensée

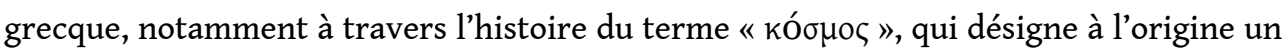
" ordre naturel autant que politique ", ainsi que le souligne J.-P. Vernant à propos des débuts de la cité. Mais cet ordre, comme condition de possibilité du débat contradictoire entre les citoyens, suscite aussi par là de la contestation, du désordre. C'est le terme xó́oৎ qui l'exprime dans les représentations religieuses archaïques, en tant qu'état indéfini, s'opposant à la mise en ordre du monde (Hésiode, Théogonie, v.

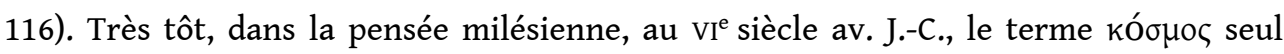
désigne le monde et, dans son acception politique, il est accompagné par les mots de la

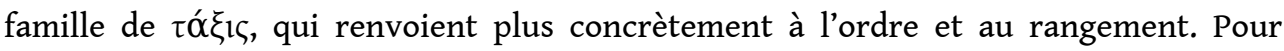

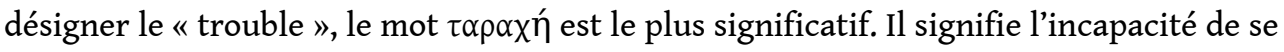
diriger, de trouver des repères, notamment, chez Thucydide, au cœur d'une bataille ou lorsque la cité est en proie au fléau, de nature médicale et politique, qui la ronge de l'intérieur (II, 52, 4). C'est l'héritage thucydidéen, avant tout politique, exprimé également dans l'Antigone de Sophocle, qui se retrouve chez Platon et Xénophon. Pour saisir l'originalité de ce moment historique, P. Pontier fait le choix de conduire une analyse systématique de l'intégralité du corpus des deux auteurs, considérés comme des sources majeures et cohérentes. Cette étude «comparative, centrée sur des notions ", ne se présente pas comme une tentative de reconstitution du dialogue perdu entre Platon et Xénophon. En prenant en compte les parentés de pensée à travers les similitudes de langage, en restant attentif à «l'hétérogénéité des genres littéraires abordés ", en posant le problème de «la réception du lectorat visé », l'auteur invite à suivre, ou plutôt construit la méthode d'une philologie historique aussi rigoureuse qu'ouverte. L'analyse et le testament politiques de Xénophon et de Platon y acquièrent ainsi une netteté particulière et constituent un matériau dont quiconque voudra prolonger l'enquête au-delà de l'Antiquité ne pourra désormais faire l'économie.

4 La première partie - "Le constat du trouble" - se présente comme un « diagnostic » des parties malades du corps social et de la cité, touchés par le "trouble» et le " désordre ». Le chapitre I analyse en détail l'expression lexicale du « trouble », à partir de l'ensemble des occurrences de thorubos (qui renvoie au tumulte de la foule et aux assemblées houleuses des procès populaires) et de tarakhè (avec sa connotation plus visuelle qu'auditive), replacés dans un double contexte : celui de l'histoire de ces termes et celui des années contemporaines de l'action et de l'écriture de Xénophon et Platon. Mais par delà l'inventaire des termes, l'analyse s'élargit pour montrer que le lexique du «trouble » est associé de façon métaphorique au registre nosographique, à partir des familles de "novso", la "maladie», et de "pavqo", "l'affection", et il s'étend à d'autres domaines, tels que le champ de bataille. On songe au constat terrible que dresse Xénophon pour décrire la situation à l'issue de la bataille de Mantinée (362 avant J.-C.), qui aurait dû apparaître comme l'évidente victoire de Thèbes sur Sparte; au contraire, selon l'historien, personne n'est en mesure de distinguer où sont les vainqueurs et qui sont les vaincus, et «l'incertitude et le trouble (akrisia de kai tarakhè) furent plus grands après qu'avant dans toute la Grèce » (Helléniques, VII, 5, 26-27). Le 
«trouble » est une donnée de l'histoire, qui est analysée comme telle dans le chapitre II. C'est en effet dans la Cyropédie et les Helléniques, dans le Critias et les Lois, œuvres des décennies 360 et 350 que le « trouble » est le plus fréquemment décrit, en rapport avec l'histoire. Ainsi chez Platon, analysant les crises de la dernière décennie du v viècle, à Athènes - la tyrannie des Trente, les procès des Arginuses, de Théramène et de Socrate -, le «tumulte» caractérise les excès de la démocratie et le «trouble» est une «caractéristique politique» de ce régime. L'analyse est également attentive aux évolutions chronologiques: la condamnation sans faille de la démocratie dans la République fait place à une critique plus nuancée du «tumulte " de la "théatrocratie " dans les Lois. Mais la condamnation, chez Platon, ne s'en tient pas aux seuls principes; elle vise aussi des personnes, les fauteurs de trouble, dont le chapitre III analyse l'action, l'influence, les réseaux: Alcibiade et Ménon, Ménétos, l'un des principaux accusateurs de Socrate, dans le procès de 399, Charmide et Calliclès, le milieu des sophistes, dont l'imposture politique (chez Protagoras) et la cuisine rhétorique (chez Hippias) sont source de trouble et de confusion.

5 À ce diagnostic les œuvres de Xénophon et de Platon apportent des remèdes concrets ou possibles, dont l'analyse est l'objet de la deuxième partie. Ceux-ci résident avant tout dans les ressources du langage à travers la dialectique qu'invente Socrate et qui se présente comme une remise en ordre. Ce discours de l'«ordre »- qui repose sur le

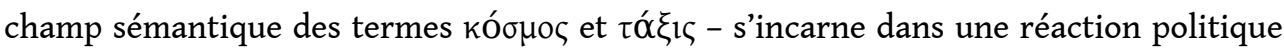
dont le lieu d'élaboration est souvent l'armée, celle de l'expédition des Dix-Mille emmenés par Xénophon lui-même, du roi spartiate Agésilas, son mentor, lieu qui est davantage, chez Platon, la cité elle-même, lorsqu'elle est dirigée par le philosophe-roi, figure de conciliateur entre le roi, la loi et l'ordre.

6 Mais la recherche de l'« ordre » ne peut être dissociée d'une réflexion sur les principes qui en assurent l'apprentissage et la diffusion, c'est-à-dire sur l'éducation et sa place dans la cité, d'autant que le "trouble" a été identifié comme venant surtout de la jeunesse. La troisième partie - "Ordre et idéal éducatif" - étudie les conceptions de Platon et de Xénophon sur ce point fondamental et leurs divergences. L'idéal éducatif

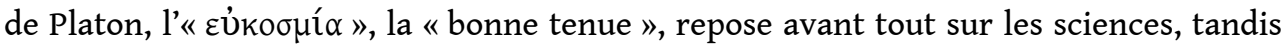

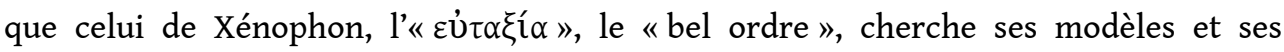
références, de nature essentiellement militaire, dans le passé de la Perse et de Sparte. La Perse de la Cyropédie et la Crète des Lois constituent néanmoins des projets proches en ce qu'ils se situent dans un monde rêvé, reflet d'une conception pessimiste, voire désenchantée, du trouble et de l'ordre face aux tumultes de l'histoire.

7 L'ensemble de l'étude met en lumière « la dimension visuelle et politique du trouble et de l'ordre» (p.433). En ce sens, ces notions s'inscrivent sur la longue durée dans la série des notions au double registre, empirique et réflexif, telles theôria, qui accompagnent le développement de la pensée grecque. Ce livre, pourvu d'une annexe qui rassemble tous les relevés lexicaux, d'une très riche bibliographie et de trois indices, sera désormais un instrument de travail et un compagnon privilégiés, en même temps qu'une référence, pour en conduire l'analyse. 


\section{AUTEURS}

PASCAL PAYEN

Université Toulouse II-Le Mirail

payen@univ-tlse2.fr 